\title{
Efficacy and safety of afatinib in Chinese patients with EGFR-mutated metastatic non-small-cell lung cancer (NSCLC) previously responsive to first-generation tyrosine-kinase inhibitors (TKI) and chemotherapy: comparison with historical cohort using erlotinib
}

Victor H. F. Lee*, Dennis K. C. Leung, Tim-Shing Choy, Ka-On Lam, Pui-Mei Lam, To-Wai Leung and Dora L. W. Kwong

\begin{abstract}
Background: Afaitnib has shown anti-tumor activity against metastatic EGFR-mutated NSCLC after prior failure to first generation EGFR-TKI and chemotherapy. We prospectively evaluated the efficacy and safety of afatinib in Chinese patients who previously failed first-generation TKI and chemotherapy under a compassionate use program (CUP) and compared to the erlotinib cohort.

Methods: Patients who suffered from metastatic EGFR-mutated NSCLC previously responsive to first-generation TKI and chemotherapy received afatinib until progression, loss of clinical benefits or intolerable toxicity. Treatment response, survival and safety were evaluated and compared to the erlotinib cohort.

Results: Twenty-five and 28 patients received afatinib and erlotinib respectively. More patients in the afatinib group had worse performance status (ECOG 2$)$ than the erlotinib group $(p=0.008)$. After a median follow-up of 12.1 months, afatinib demonstrated comparable objective response rate (ORR) (20.0 \% vs. $7.1 \%, p=0.17)$ but significantly higher disease control rate (DCR) $(68.0 \%$ vs. $39.3 \%, p=0.04)$ compared to erlotinib. Median progression-free survival (PFS) (4.1 months [95 \% Cl, 2.7-5.5 months] vs. 3.3 months [95 \% Cl, 2.2-4.3 months], $p=0.97$ ) and overall survival (OS) were not different between the two groups (10.3 months [95\% Cl, 7.5-13.0 months] vs. 10.8 months [95 \% Cl, 7.4-14.2 months], $p=0.51$ ). Multivariate analyses revealed that age $\leq 70$ years and time to progression (TTP) $\geq 18$ months for the $1^{\text {st }}$ TKI therapy were prognostic of PFS ( $p=0.006$ and $p=0.008$ respectively). Afatinib caused less rash ( $60.0 \%$ vs. $67.9 \%, p=0.04$ ) but more diarrhea (60.0 \% vs. $10.7 \%, p=0.002)$ compared to erlotinib.
\end{abstract}

Conclusion: Afatinib produced encouraging clinical efficacy as $2^{\text {nd }}$ TKl therapy with manageable safety profiles in our Chinese patients after failure to another TKI and systemic chemotherapy.

This study was registered at ClinicalTrials.gov (NCT02625168) on $3^{\text {rd }}$ December 2015.

Keywords: Afatinib, Erlotinib, Epidermal growth factor receptor mutation, Tyrosine-kinase inhibitor, Non-small-cell lung cancer

\footnotetext{
* Correspondence: vhflee@hku.hk

Department of Clinical Oncology, Li Ka Shing Faculty of Medicine, Queen

Mary Hospital, The University of Hong Kong, 1/F, Professorial Block, 102

Pokfulam Road, Hong Kong, China
}

C 2016 Lee et al. Open Access This article is distributed under the terms of the Creative Commons Attribution 4.0 International License (http://creativecommons.org/licenses/by/4.0/, which permits unrestricted use, distribution, and reproduction in any medium, provided you give appropriate credit to the original author(s) and the source, provide a link to the Creative Commons license, and indicate if changes were made. The Creative Commons Public Domain Dedication waiver (http://creativecommons.org/publicdomain/zero/1.0/) applies to the data made available in this article, unless otherwise stated. 


\section{Background}

First-generation epidermal growth factor receptor tyrosinekinase inhibitors (EGFR-TKI) including geiftinib and erlotinib have been the standard first-line treatment for metastatic non-small-cell lung cancer (NSCLC) harboring activating EGFR mutation. Global and regional phase III randomized-controlled trials demonstrated that the median progression-free survival (PFS) after gefitinib or erlotinib ranged from 9 to 13 months with the longest PFS of 13.1 months seen in OPTIMAL study using erlotinib [1-7]. Emergence of T790M mutation is the most common mechanism of acquired resistance to EGFR-TKI, accounting for about $50-60 \%$ of patients who developed disease progression after EGFR TKI [8-10].

Afatinib, regarded as second-generation EGFR-TKI, is an irreversible ErbB family blocker. It was approved as first-line treatment for EGFR-mutated advanced NSCLC in European Union and some other countries in 2013. It exhibits an inhibitory effect on T790M-mutated NSCLC in in-vitro studies, apart from the expected inhibition on exon 19 deletion and $L 858 R$ point mutation [11, 12]. The LUX-Lung1 study published in 2010 has demonstrated efficacy with improvement in progression-free survival (3.3 months) for those who had taken afatinib $50 \mathrm{mg}$ daily compared to those who had placebo, after previous treatment with gefitinib or erlotinib for at least 12 weeks and at least one line of platinum-based chemotherapy [13]. More recently, Khan et al. also revealed similar efficacy of afatinib in the same clinical setting in a Named Patient Use (NPU) program conducted in the United Kingdom [14]. To the best of our knowledge, there has been so far no randomized-controlled trials comparing the efficacy of afatinib with gefitinib/erlotinib (collectively grouped as first-generation EGFR-TKI in the latter text) in those who had prior failure to first-generation EGFRTKI for their metastatic EGFR-mutated NSCLC. For the current analysis, we prospectively evaluated the efficacy and safety profiles of afatinib as $3^{\text {rd }}$ or $4^{\text {th }}$ line treatment after prior failure to systemic chemotherapy and first-generation EGFR-TKI under a Boehringer Ingelheim sponsored Compassionate Use Program (CUP), with comparison of our historical cohort who received erlotinib after previous failure to systemic chemotherapy and first-generation EGFR-TKI.

\section{Methods}

\section{Study design}

This study was approved by the ethics committee of the University of Hong Kong/Hospital Authority Hong Kong West Cluster (Reference number UW 13-396). It was commenced in January 2013 with the last patient recruited in February 2014. All patients gave their written informed consent before recruitment into this study. We prospectively evaluated the use of afatinib as $3^{\text {rd }}$ or $4^{\text {th }}$ line treatment after progression to one line of firstgeneration EGFR-TKI therapy and one to two lines of systemic chemotherapy under this CUP. All patients had documented EGFR activating mutations before the start of afatinib. Determination of EGFR mutation analysis of all patients was described previously [15]. Formalin-fixed paraffin-embedded tumor biopsies before starting $1^{\text {st }}$ TKI therapy were retrieved. Briefly, tumor enrichment was performed by micro-dissection under light microscopy. Genomic DNA was extracted using QIAmp DNA FFPE Tissue kit (Qiagen, Hilden, Germany), followed by polymerase chain reaction (PCR) amplification of EGFR exons 18 to 21 using intron-based primers and sequenced in both forward and reverse directions. The last date of data capture for statistical analysis was on $31^{\text {st }}$ March 2015. The trial was registered with ClinicalTrials.gov (NCT02625168).

\section{Study population}

Patients who had EGFR-mutated metastatic NSCLC with prior documented objective response to first-generation TKI (gefitinib or erlotinib) for 6 months and prior treatment of at least 1 line of systemic chemotherapy were eligible to join the CUP offered by Boehringer-Ingelheim Pharma GmbH, Ingelheim, Germany. Patients who had received anti-vascular endothelial growth factor antagonist but not anti-EGFR monoclonal antibody in their previous courses of treatment, either alone or in combination with systemic chemotherapy were allowed to join this CUP. In addition, patients who had asymptomatic brain metastases who had not been on corticosteroids for the treatment of their brain metastases for at least 14 days prior to afatinib or erlotinib treatment were also eligible for this study. All recruited patients had baseline computed tomography scan of the brain, thorax and abdomen with at least 1 evaluable target lesion defined by Response Evaluation Criteria for Solid Tumors (RECIST) version 1.1 and adequate serum hematological, hepatic and renal function as defined by LUX-Lung1 study [16].

\section{Treatment}

The treating physicians then decided the starting dose of afatinib of either $50 \mathrm{mg}, 40 \mathrm{mg}$ or $30 \mathrm{mg}$ once daily continuously. After commencement of afatinib, they had regular clinical follow up every 2 weeks for 4 weeks then every 4 weeks until permanent discontinuation of afatinib or death. They also had regular imaging with computed tomography (CT) scan every 8-10 weeks for tumor response evaluation according to RECIST version 1.1 performed by two independent board certified radiologists blinded to study treatment [16]. Any discrepancies between the two radiologists on tumor response assessment were resolved by consensus. Treatment interruption was needed for those who developed grade $\geq 3$ 
Table 1 Patient characteristics

\begin{tabular}{llll}
\hline & $\begin{array}{l}\text { Afatinib } \\
(n=25)(\%)\end{array}$ & $\begin{array}{l}\text { Erlotinib } \\
(n=28)(\%)\end{array}$ & $p$-value \\
\hline Age (range) & 63 & 59 & 0.59 \\
& $(42-85)$ & $\begin{array}{l}(36-80) \\
\text { Sex (male/female) }\end{array}$ & \\
ECOG & $11 / 14$ & $10 / 18$ & 0.54 \\
0 & & & \\
1 & $1(4.0)$ & $0(0.0)$ & 0.01 \\
2 & $12(48.0)$ & $24(85.7)$ & \\
$0 / 1$ vs. 2 & $12(48.0)$ & $4(14.3)$ & \\
& $13(52.0)$ & $24(85.7)$ & 0.008 \\
& vs. 12(48.0) & vs. $4(14.3)$ &
\end{tabular}

Smoking status

$\begin{array}{lll}\text { Never smokers } & 22(88.0) & 25(89.3) \\ \text { Current or past smokers } & 3(12.0) & 3(10.7)\end{array}$

Histology

$\begin{array}{lll}\text { Adenocarcinoma } & 23(92.0) & 28(100.0) \\ \text { Squamous cell carcinoma } & 1(4.0) & 0(0.0) \\ \text { Bronchoalveolar carcinoma } & 1(4.0) & 0(0.0)\end{array}$

Initial EGFR mutation

status at diagnosis

$\begin{array}{lll}\text { exon } 18 \text { mutation } & 0 & 1 \\ \text { exon } 19 \text { deletion } & 11 & 13 \\ \begin{array}{l}\text { exon } 19 \text { substitution } \\ \text { mutation }\end{array} & 1 & 1 \\ \text { L858R } & 8 & 10 \\ \text { L861Q } & 0 & 2 \\ \text { double mutations } & 1 & 1\end{array}$

EGFR mutation status with re-biopsy before afatinib or erlotinib

T790M alone
Brain metastasis before
afatinib or erlotinib
$1^{\text {st }}$ TKI therapy
Gefitinib
Erlotinib
Median duration of
therapy (months, range)
Median Time to progression
(months range)
Best response
CR
PR
SD
PD

Number of lines of prior

chemotherapy before

afatinib or erlotinib

$\begin{array}{lll}4 & \text { unknown } & \text { NA } \\ 6(24.0) & 13(46.4) & 0.09\end{array}$

0.88

0.31

0.79

3

$$
\begin{array}{lll}
1 & 14(56.0) & 22(78.6) \\
2 & 11(44.0) & 6(21.4)
\end{array}
$$

\begin{tabular}{|c|c|c|c|}
\hline $\begin{array}{l}\text { First-line chemotherapy before } \\
\text { afatinib or erlotinib }\end{array}$ & $25(100)$ & $28(100)$ & 0.88 \\
\hline Pemetrexed + cisplatin & $3(12.0)$ & $6(21.4)$ & \\
\hline Pemetrexed + carboplatin & $9(36.0)$ & $7(25.0)$ & \\
\hline Paclitaxel + carboplatin & $4(16.0)$ & $4(14.3)$ & \\
\hline Gemcitabine + carboplatin & $5(20.0)$ & $5(17.9)$ & \\
\hline Carboplatin & $2(8.0)$ & $2(7.1)$ & \\
\hline Pemetrexed & $2(8.0)$ & $4(14.3)$ & \\
\hline $\begin{array}{l}\text { Median duration of } \\
\text { therapy (months, range) }\end{array}$ & $\begin{array}{l}3.50 \\
(0.69-17.97)\end{array}$ & $\begin{array}{l}2.96 \\
(0.66-17.02)\end{array}$ & 0.85 \\
\hline $\begin{array}{l}\text { Median time to progression } \\
\text { (months, range) }\end{array}$ & $\begin{array}{l}3.35 \\
(0.69-17.97)\end{array}$ & $\begin{array}{l}3.48 \\
(0.85-16.95)\end{array}$ & 0.76 \\
\hline $\begin{array}{l}\text { Second-line chemotherapy before } \\
\text { afatinib or erlotinib }\end{array}$ & $11(44.0)$ & $6(21.4)$ & 0.08 \\
\hline Pemetrexed + carboplatin & $1(4.0)$ & $0(0.0)$ & \\
\hline Paclitaxel + carboplatin & $2(8.0)$ & $2(7.1)$ & \\
\hline Gemcitabine + carboplatin & $5(20.0)$ & $4(14.3)$ & \\
\hline Docetaxel & $1(4.0)$ & $0(0.0)$ & \\
\hline Vinorelbine & $1(4.0)$ & $0(0.0)$ & \\
\hline Pemetrexed & $1(4.0)$ & $0(0.0)$ & \\
\hline $\begin{array}{l}\text { Median duration of } \\
\text { therapy (months, range) }\end{array}$ & $\begin{array}{l}2.30 \\
(0.66-9.63)\end{array}$ & $\begin{array}{l}2.92 \\
(0.69-4.34)\end{array}$ & 0.91 \\
\hline $\begin{array}{l}\text { Median time to progression } \\
\text { (months, range) }\end{array}$ & $\begin{array}{l}3.09 \\
(0.66-10.28)\end{array}$ & $\begin{array}{l}3.25 \\
(0.72-4.44)\end{array}$ & 0.74 \\
\hline $\begin{array}{l}\text { Median time interval between } \\
1^{\text {st }} \text { TKI therapy and afatinib } \\
\text { or erlotinib (months, range) }\end{array}$ & $\begin{array}{l}8.38 \\
(2.30-54.28)\end{array}$ & $\begin{array}{l}6.39 \\
(2.56-20.07)\end{array}$ & 0.15 \\
\hline $\begin{array}{l}\text { Median time interval between } \\
\text { last chemotherapy and afatinib } \\
\text { or erlotinib (months, range) }\end{array}$ & $\begin{array}{l}2.79 \\
(0.46-34.28)\end{array}$ & $\begin{array}{l}2.58 \\
(0.23-17.05)\end{array}$ & 0.49 \\
\hline
\end{tabular}

Table 1 Patient characteristics (Continued)

Abbreviations: $C R$ complete response, EGFR epidermal growth factor receptor, $N A$ not applicable, $P D$ progressive disease, $P R$ partial response, $S D$ stable disease, TKI tyrosine-kinase inhibitor

adverse event until it was returned to grade 1 or less. Then afatinib could be resumed but at a one lower dose level. Those who received afatinib $30 \mathrm{mg}$ daily as the initial starting dose would discontinue afatinib permanently if they developed grade $\geq 3$ events.

\section{Assessment of efficacy and safety profiles}

All treatment-related toxicities were collected and graded according to Common Terminology Criteria for Adverse Events (CTCAE) version 4.0 [17]. Objective response (OR) included complete response and partial response while disease control (DC) included complete response, partial response and stable disease according to RECIST 1.1. The primary study endpoint was PFS, defined as time from the date of start of afatinib to the date of objectively determined progressive disease or death from any cause). Secondary study endpoints were overall survival (OS, time from the date of start of afatinib to date of death from any 
cause), time to progression (TTP) started from the date of afatinib commencement to the date of objectively determined progressive disease and safety profiles. All these parameters of all patients in the afatinib group in this study were compared to a historical cohort of all patients who received erlotinib after prior failure to gefitinib and at least one line of systemic chemotherapy in our department from January 2009 to December 2011, with the same inclusion and exclusion criteria as for the patients who received afatinib in this study. All patients in this erlotinib historical cohort received erlotinib at $150 \mathrm{mg}$ once daily, and they were assessed by the same imaging modalities for treatment response evaluation, as well the same departmental protocol for safety profiles and survival outcomes as for those who received afatinib in this study.

\section{Statistical analysis}

Mann-Whitney U tests were used for comparison of non-parametric variables and chi-square tests were performed for baseline and posttreatment discrete variables. Kaplan-Meier methods with log-rank tests were employed for comparison of each prespecified survival endpoints and Cox proportional hazard models were used for prognostic factors for PFS after afatinib or erlotinib in univariate and multivariate analyses, with afatinib versus erlotinib, age, sex, performance status, smoking status, histology, TTP for $1^{\text {st }}$ TKI therapy, time interval between $1^{\text {st }}$ TKI and afatinib or erlotinib, TTP for all lines of prior chemotherapy, time interval between last chemotherapy and afatinib or erlotinib as covariates. All statistical analyses were performed by Statistical Package for Social Sciences (SPSS) version 20 (SPSS, Inc., Chicago, IL, USA).

\section{Results}

\section{Patient characteristics}

The patient characteristics were shown in Table 1. The median follow-up duration was 12.1 months (range 4.1-28.7 months) for the afatinib group and 12.2 months (range 0.4-48.7 months) for the erlotinib group. Twentyfive and 28 patients received afatinib and erlotinib respectively in this study after initial failure to firstgeneration TKI and chemotherapy. Six $(24.0 \%)$ and 13 (46.4\%) patients in the afatinib and erlotinib group respectively had asymptomatic brain metastases at baseline. They all had either gross tumor removal or radiation therapy for their brain metastases before study commencement. Four patients in the afatinib group had tumor re-biopsy before commencing afatinib and their recurrent tumors all harbored $T 790 M$ mutation in addition to exon 19 deletion. Of them, one had a further $L 883 \mathrm{~V}$ mutation on exon 21 and another patient had small cell transformation.
More patients in the afatinib group had worse Eastern Cooperative Oncology Group (ECOG) performance status 2 compared to the erlotinib group $(p=0.008)$. Also the median duration of $1^{\text {st }}$ TKI therapy was longer in the afatinib group (14.5 vs. 9.2 months, $p=0.02$ ). Two, 21 and 2 patients received afatinib $50 \mathrm{mg}, 40 \mathrm{mg}$ and $30 \mathrm{mg}$ daily respectively while all patients in the erlotinib group received erlotinib at $150 \mathrm{mg}$ daily as the starting dose.

\section{Treatment efficacy}

ORR for afatinib was $20.0 \%$ while that for erlotinib was $(7.1 \%, p=0.17)$ (Table 2). DCR was higher with afatinib $(68.0 \%)$ than with erlotinib $(39.3 \%, p=0.04)$. ORR of brain metastases was similar between the afatinib group $(12.0 \%)$ and the erlotinib group $(14.3 \%, p=0.81)$. Time to progression and the duration of treatment of two TKI groups did not differ. Median PFS for the afatinib group was 4.1 months (95\% confidence interval $[\mathrm{CI}], 2.7-5.5$ months) and 3.3 months $(95 \% \mathrm{CI}$, 2.2-4.4 months) for the erlotinib group $(p=0.97)$ (Fig. 1a). Median OS was also similar, 10.3 months (95\% CI, 7.5-13.0 months) for afatinib group and 10.8 months (95\% CI, 7.4-14.2 months) for erlotinib $(p=0.51)$ (Fig. 1b). More patients in the afatinib group received the respective TKI beyond radiological progression until symptomatic progression $(39.1 \%$ vs. $14.8 \%, p=0.05) .2(8.0 \%)$ patients in the afatinib group and $1(5.6 \%)$ patient in the erlotinib group were still receiving their respective TKI without disease progression at the time of publication.

Table 2 Treatment outcomes in afatinib and erlotinib arm

\begin{tabular}{|c|c|c|c|}
\hline & Afatinib (\%) & Erlotinib (\%) & $p$-value \\
\hline Best response & & & 0.09 \\
\hline$C R$ & $0(0.0)$ & $0(0.0)$ & \\
\hline PR & $5(20.0)$ & $2(7.1)$ & \\
\hline SD & $12(48.0)$ & $9(32.1)$ & \\
\hline PD & $8(32.0)$ & $17(60.7)$ & \\
\hline Objective response rate & $5(20.0)$ & $2(7.1)$ & 0.17 \\
\hline Disease control rate & $17(68.0)$ & $11(39.3)$ & 0.04 \\
\hline $\begin{array}{l}\text { Objective response of } \\
\text { brain metastases }\end{array}$ & $3(12.0)$ & $4(14.3)$ & 0.81 \\
\hline $\begin{array}{l}\text { Median duration of } \\
\text { treatment (months, range) }\end{array}$ & $\begin{array}{l}4.5 \\
(0.2-22.7)\end{array}$ & $\begin{array}{l}3.3 \\
(0.3-48.7)\end{array}$ & 0.52 \\
\hline $\begin{array}{l}\text { Median time to } \\
\text { progression (months, range) }\end{array}$ & $\begin{array}{l}3.3 \\
(0.2-12.6)\end{array}$ & $\begin{array}{l}3.3 \\
(0.3-14.4)\end{array}$ & 0.77 \\
\hline $\begin{array}{l}\text { Median PFS (95 \% Cl) } \\
\text { (months) }\end{array}$ & $4.1(2.7-5.5)$ & $3.3(2.2-4.4)$ & 0.97 \\
\hline $\begin{array}{l}\text { Median OS (95 \% Cl) } \\
\text { (months) }\end{array}$ & $\begin{array}{l}10.3 \\
(7.5-13.0)\end{array}$ & $\begin{array}{l}10.8 \\
(7.4-14.2)\end{array}$ & 0.51 \\
\hline
\end{tabular}

Abbreviations: $C l$ confidence interval, $C R$ complete response, $P D$ progressive disease, $P F S$ progression-free survival, $P R$ partial response, $S D$ stable disease, TKI tyrosine-kinase inhibitor 


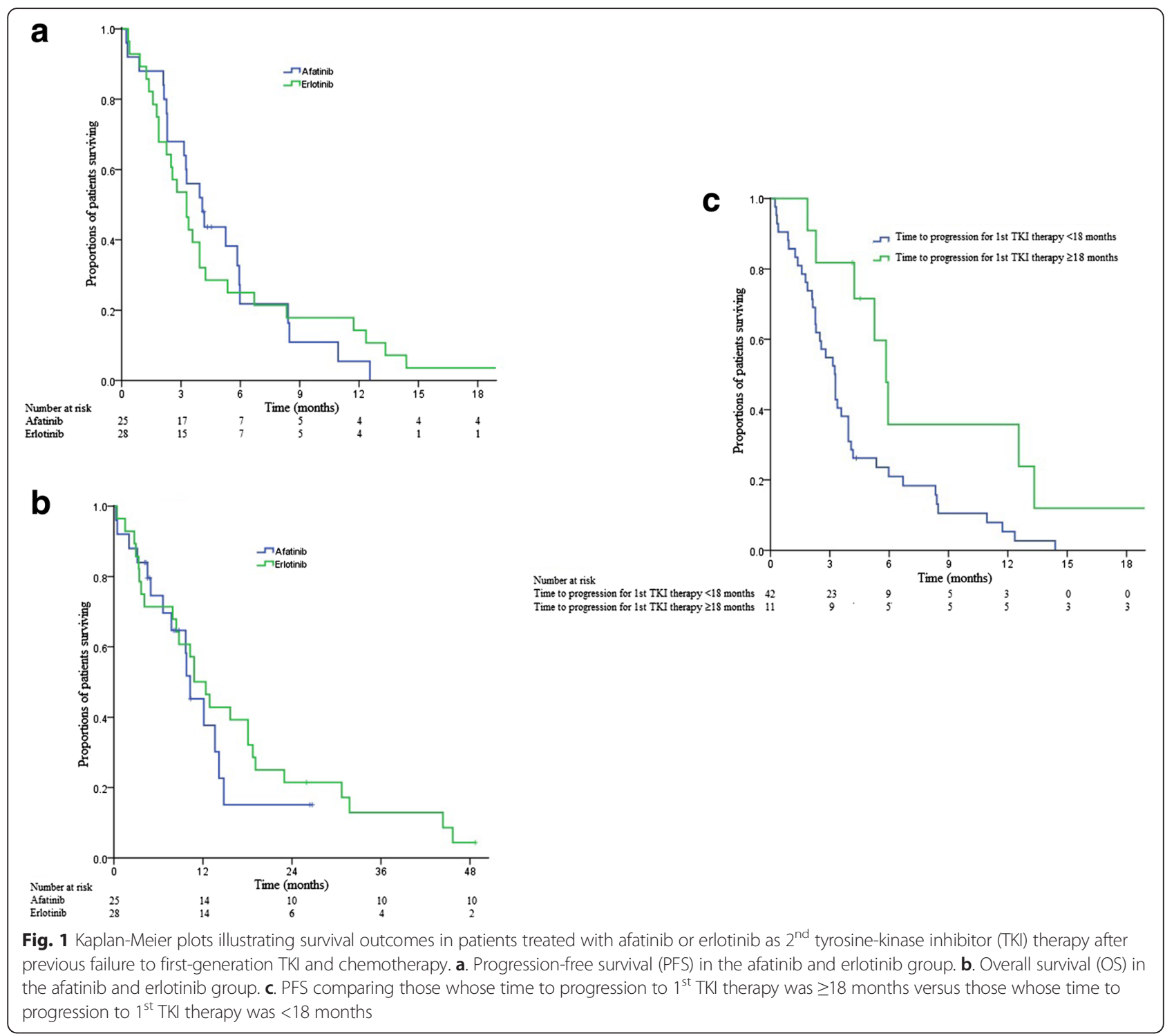

In the afatinib group, median PFS was similar between those with exon 19 deletion (3.9 months [95\% CI, 2.2-5.7 months]) and L858R mutation (4.1 months [95 \% CI, 1.5-6.7 months], $p=0.94)$. Insignificant difference in median PFS was also noted between patients with exon 19 deletion (3.6 months [93 \% CI, 2.3-4.9 months]) and L858R mutation (2.5 months [95 \% CI, 1.33.7 months], $p=0.31$ ) in the erlotinib cohort. In addition, afatinib was not found to produce longer median PFS (4.2 months [95 \% CI, 1.2-7.2 months]) than erlotinib in patients whose tumors exhibited exon 19 deletion (3.6 months [95\% CI, 2.2-4.9 months, $p=0.70$ ). Similarly no statistical significance in median OS was noted between patients who received afatinib (14.2 months [95 \% CI, 6.0-22.3 months]) and who received erlotinib
(18.1 months [95 \% CI, 9.7-26.4 months], $p=0.28$ ) for their tumors which harbored exon 19 deletion. No PFS or OS advantage with afatinib was also noticed in those who had L858R mutation in their tumous compared to those who received erlotinib.

In particular, one of our study patients with previous gefitinib- and chemotherapy-responsive metastatic bronchoalveolar carcinoma which harbored exon 19 deletion had a dramatic and long-lasting response to afatinib for 12.6 months before further disease progression (Fig. 2). For the 4 patients with documented T790M mutation before starting afatinib, 1 had partial response (T790M and exon 19 deletion), 2 had stable disease (one with T790M, exon 19 deletion and small cell carcinoma and the other with $T 790 M$, exon 19 deletion and $L 833 \mathrm{~V}$ 

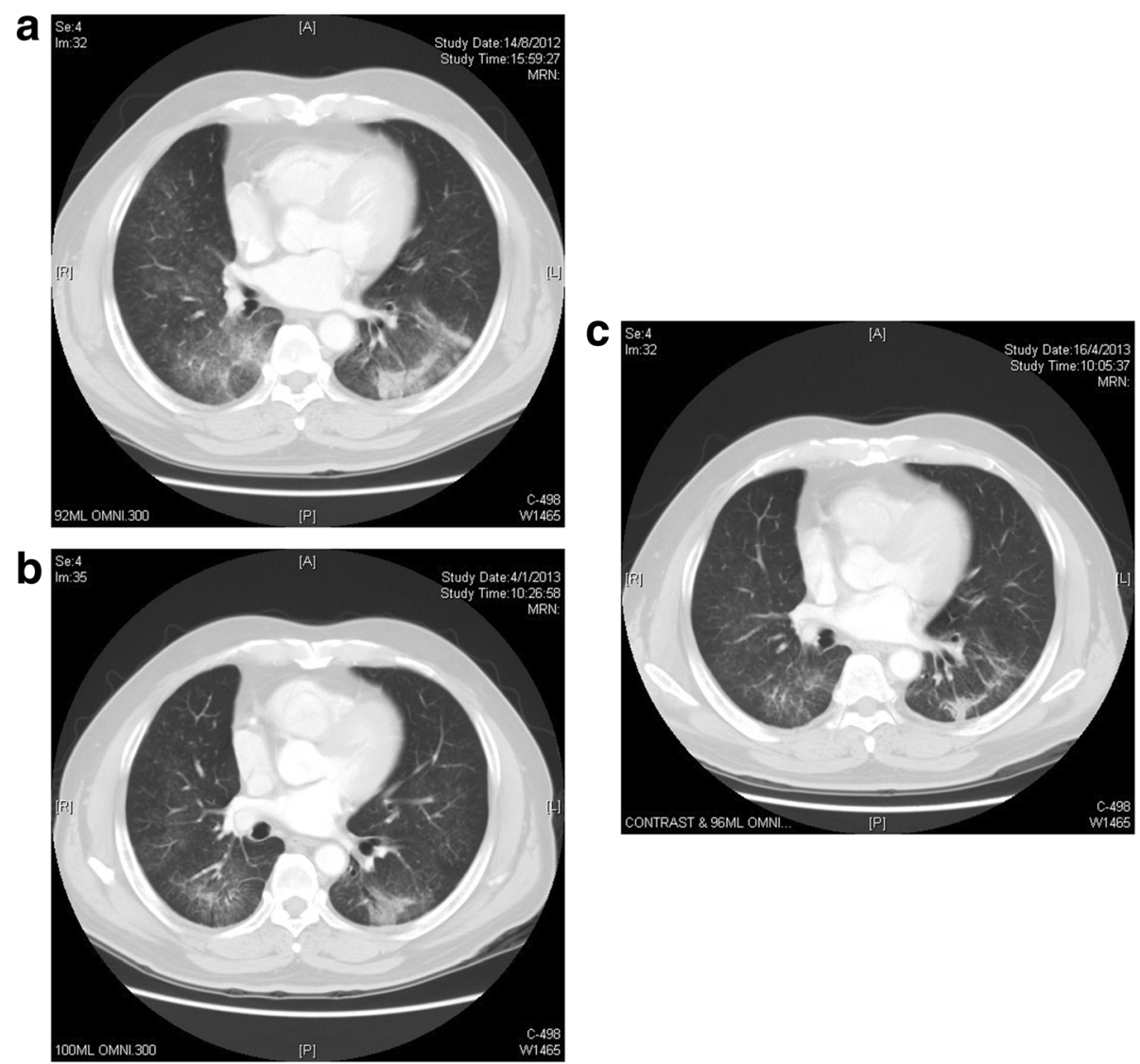

Fig. 2 Computed tomography images of one of our study patients with metastatic bronchoalveolar carcinoma which harbored exon 19 deletion treated with afatinib as $2^{\text {nd }}$ TKI therapy after failure to gefitinib and chemotherapy. $\mathbf{a}$. Baseline images showing diffuse ground glass opacities representing tumor infiltrates in lower lobes of both lungs. b. CT images at 3 months after afatinib showing significant reduction of tumor infiltrates. c. CT images at 6 months after afatinib showing further response and tumor shrinkage to afatinib

mutation) and the remaining 1 patient (T790M, exon 19 deletion and $L 833 \mathrm{~V}$ mutation) had his disease progressed with afatinib. Their TTP ranged from 2.3 to 6.0 months.

\section{Univariate and multivariate analysis of PFS and OS}

Univariate analysis revealed that age $\leq 70$ years (Hazard ratio [HR], 0.50; $95 \% \mathrm{CI}, 0.25-0.86, p=0.008)$ and TTP to $1^{\text {st }}$ TKI therapy for $\geq 18$ months (HR, 0.38; $95 \% \mathrm{CI}$, $0.18-0.83, p=0.01$ ) conferred a longer PFS for afatinib or erlotinib as $2^{\text {nd }}$ TKI therapy (Table 3 ). They were also the only prognostic factors for PFS in multivariate analysis (HR, 0.48; $95 \% \mathrm{CI}, 0.21-0.74, p=0.006$ and $\mathrm{HR}$, 0.39 ; $95 \%$ CI, $0.16-0.80 ; p=0.008$ respectively). The median PFS for afatinib or erlotinib in patients whose TTP to $1^{\text {st }}$ TKI therapy $\geq 18$ months was 5.8 months (95\% CI, 4.9-6.8 months) as compared to 3.3 months (95\% CI, 2.5-4.0 months) in patients whose TTP to $1^{\text {st }}$ TKI therapy $<18$ months (Fig. 1c). No parameters were identified as significant prognostic factors for OS.

\section{Post-discontinuation treatment}

Seven $(28.0 \%)$ and $10(35.7 \%)$ patients in the afatinib and erlotinib group respectively received further systemic chemotherapy after cessation of their respective TKI therapy, without any statistical significance $(p=0.55)$. Similarly, $2(8.0 \%)$ and $2(7.1 \%)$ patients in the afatinib and erlotinib group respectively received another TKI therapy following discontinuation of their afatinib/erlotinib therapy $(p=0.91)$. All patients had only 1 line of post-discontinuation chemotherapy or TKI following cessation of afatinib/erlotinib, except that 2 patients (1 in afatinib group and 1 in erlotinib group) who received 2 lines of post-discontinuation chemotherapy. The number of lines of post-discontinuation chemotherapy and TKI did not differ between the two TKI groups $(p=0.53$ and $p=0.91$ respectively).

\section{Toxicity profiles}

Treatment-related toxicities differed for afatinib as compared to erlotinib group, as shown in Table 4. Acneiform rash (both all grades and grade $\geq 3$ events) was more 
Table 3 Univariate and multivariate analyses of prognostic markers for PFS

\begin{tabular}{lcl}
\hline & $\begin{array}{c}\text { Univariate analysis } \\
(p \text {-value })\end{array}$ & $\begin{array}{l}\text { Multivariate analysis } \\
(p \text {-value })\end{array}$ \\
\hline Afatinib vs. erlotinib & 0.97 & $\mathrm{ND}$ \\
Age $\leq 70$ years & 0.008 & 0.006 \\
Sex & 0.79 & $\mathrm{ND}$ \\
Smoking status & 0.25 & $\mathrm{ND}$ \\
Histology & 0.62 & $\mathrm{ND}$ \\
Performance status & 0.66 & $\mathrm{ND}$ \\
$\begin{array}{l}\text { Time to progression for } \\
1^{\text {st }} \text { TKI therapy }\end{array}$ & 0.09 & 0.06 \\
$\begin{array}{l}\text { Time to progression } \geq 18 \text { months } \\
\text { for } 1^{\text {st }} \text { TKl therapy }\end{array}$ & 0.01 & 0.008 \\
$\begin{array}{l}\text { Time to progression for all } \\
\text { lines of chemotherapy treatment } \\
\text { before } 2^{\text {nd }} \text { TKl therapy }\end{array}$ & 0.41 & $\mathrm{ND}$ \\
$\begin{array}{l}\text { Time interval between end of } \\
1^{\text {st }} \text { TKl therapy and start of } \\
\text { afatinib or erlotinib }\end{array}$ & 0.40 & $\mathrm{ND}$ \\
$\begin{array}{l}\text { Time interval between end of } \\
\text { last chemotherapy treatment } \\
\text { and start of afatinib or erlotinib }\end{array}$ & & \\
\hline
\end{tabular}

Note: Only covariates found significant in univariate analysis $(p<0.1)$ were considered in multivariate analysis

Abbreviations: ND not done, TKI tyrosine-kinase inhibitor

commonly seen with erlotinib than with afatinib. However diarrhea was the more frequent and dose-limiting complication in patients who received afatinib, leading to hypokalemia in 2 patients. Their diarrhea completely subsided after temporary afatinib suspension and the dose of afatinib was subsequently reduced from $40 \mathrm{mg}$ daily to $30 \mathrm{mg}$ daily. No recurrence of grade 3 diarrhea occurred following this dose reduction. In addition, more patients who received afatinib were found to have impaired liver function. However this was limited to grade 1 event only with no grade $\geq 2$ events. Treatment interruption was similar between the afatinib and erlotinib group ( $28.0 \%$ vs. $28.6 \%$ respectively, $p=0.96$ ). Dose reduction secondary to treatment-related complications did not differ between the two groups neither $(24.0 \%$ vs. $17.9 \%, p=0.58$ ). No patients in either group discontinued afatinib or erlotinib respectively due to treatment-related toxicity.

\section{Discussion}

Though first-generation EGFR-TKI with gefitinib or erlotinib has been the standard first-line treatment for metastatic EGFR-mutated NSCLC as demonstrated in various phase 3 randomized-controlled clinical trials [1-7], resistance against these first-generation TKI eventually develops after a median treatment duration of 9 to 13 months. It is believed to originate from the emergence of clones with the ability of generating genetic alterations which have survival advantages under the selective pressure of the current TKI treatment [18]. The most common mechanism of acquired resistance is the presence of $T 790 M$ mutation on exon 20, accounting for about $50-60 \%$ of known mutations of acquired TKI resistance [8-10]. When T790M mutation was introduced in vitro into sequences that contained exon 19 deletion and $L 858 R$ mutation, the resultant proteins were found more resistant to gefitinib in the constructs which contained T790M [9]. Afatinib was found effective in reducing tumor size in transgenic mice with T790M-L858R mutation and other exon 20 insertion EGFR mutations [11]. Other mechanisms of acquired resistance to TKI include $M E T$ amplification, HER amplification, small cell transformation and rarely secondary mutations for instance $B R A F$ mutation have been implicated [8, 19-24]. Rebiopsy of growing tumors after progression to $1^{\text {st }}$ TKI therapy has caught rising attention recently and enabled us to comprehend the change in mutation patterns which may better predict the overall prognosis and guide subsequent therapy $[10,25]$. In our study, 4 of our patients had documented posttreatment $T 790 M$ mutation with or without extra mutations in addition to the pre-existing pretreatment EGFR mutations before commencement of afatinib. One had partial response, two had stable disease and the last patient had disease progression after afatinib. This

Table 4 Treatment-related toxicity profiles

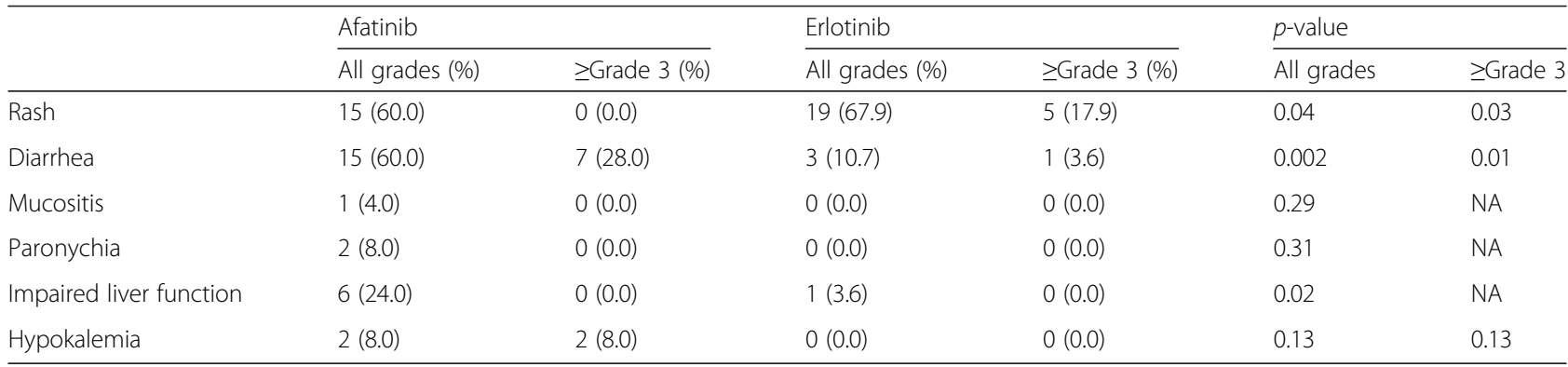


echoed with previous findings that afatinib exhibited some antitumor activity against T790M mutation.

Strategies to treat EGFR-mutated NSCLC with acquired resistance to initial TKI therapy have been continuously evolving. Rechallenge with gefitinib or erlotinib in previously TKI-responsive NSCLC upon disease progression was able to slow down the pace of clinical deterioration and stabilization of enlargement of some lesions [26, 27]. More recently two Korean studies tested the clinical efficacy of erlotinib after initial failure to gefitinib and demonstrated the very modest and limited antitumor activity, unfortunately the median time to progression was around 2 months and more than $70 \%$ of patients developed progressive disease $[28,29]$. Another small study also echoed the short duration of treatment with the dismal median PFS of 2 months [30].

Afatinib has been studied in patients with prior failure to first-generation TKI. In the phase II/III LUX-Lung 1 study, significant improvement in median PFS from 1.1 to 3.3 months was revealed as compared to placebo despite a lack of improvement in OS [13]. It was found to be more potent against T790M compared to firstgeneration TKI. The treatment results of our study was also comparable with that in LUX-Lung1 study (Table ${ }_{5}$ ). However its efficacy was limited by more potent inhibition against wild-type EGFR and subsequent toxicity which impairs the delivery of adequate dosing to the tumors [13]. In our study, diarrhea was the leading and dose-limiting complication which necessitated treatment interruption and dose reduction. However, acneiform rash was less common and severe with afatinib compared to erlotinib in our study, which might be a special feature in Chinese patients (Table ${ }_{5}$ ). Another pan-HER inhibitor dacomitinib was also investigated in this setting after prior failure to first-generation TKI in the National Cancer Institute of Canada BR.26 trial but it failed to meet its primary survival endpoint, though the outcome in the EGFR mutant subgroup remains to be reported [31]. Third-generation TKI specially designed to block T790M including CO-1686 and AZD9291 have been evolving and tested currently in phase II/III trials [32, 33]. In 2015, the phase Ib/II studies on CO-1686 and AZD9291 demonstrated an extremely encouraging objective response rate of 29 and $21 \%$ respectively in patients without T790M mutation and 59 and $61 \%$ respectively in patients with $T 790 M$ mutation [34, 35]. This has resulted in recent approval of AZD9291 for the treatment of patients who develop T790M mutation in their metastatic NSCLC by Food and Drug Administration (FDA) of the United States. More interestingly, they lacked the activity against wild-type EGFR leading to relatively fewer incidences of rash and diarrhea. Another approach for maximizing inhibition against acquired resistance is the combination of EGFR-TKI and
Table 5 Comparison of baseline patient characteristics, treatment outcomes and selected toxicity profiles after afatinib as $2^{\text {nd }}$ TKI therapy in LUX-Lung1 and current study

\begin{tabular}{lll}
\hline & LUX-Lung1 study & Current study \\
\hline Number of patients & 390 & 25 \\
Age (range) & $58(30-85)$ & $63(42-85)$ \\
Male/female (\%) & $159(40.8) / 231(59.2)$ & $11(44.0) / 14(56.0)$
\end{tabular}

ECOG performance status (\%)

$\begin{array}{lll}0 & 92(23.6) & 1(4.0) \\ 1 & 268(68.7) & 12(48.0) \\ 2 & 30(7.7) & 12(48.0)\end{array}$

Prior EGFR-TKI therapy (\%)

$\begin{array}{lll}\text { Erlotinib } & 215(55.1) & 14(56.0) \\ \text { Gefitinib } & 152(39.0) & 11(44.0) \\ \text { Both } & 23(5.9) & 0(0)\end{array}$

Number of lines of prior chemotherapy (\%)

$\begin{array}{lll}1 & 231(59.2) & 14(56) \\ 2 & 156(40.0) & 11(44) \\ 3 & 3(0.8) & 0(0)\end{array}$

Objective response (\%)

Partial response

$29(7.4)$

$5(20.0)$

Stable disease

$198(50.8)$

$12(48.0)$

Disease control (\%)

$227(58.2)$

$17(68.0)$

Median progression-free survival in months (range)

$3.3(2.8-4.4)$

$4.1(2.7-5.5)$

Median overall survival in months (range)

Selected toxicity

profiles (\%)

Rash

Diarrhea

Mucositis/stomatitis

$10.8(10.0-12.0)$

$10.3(7.5-13.0)$

Paronychia/nail effect

Hypokalemia

$\begin{array}{llll}\text { All } & \geq \text { Grade } & \text { All } & \geq \text { Grade } \\ \text { grades (\%) } & 3(\%) & \text { grades (\%) } & 3(\%) \\ 305(78.2) & 56(14.4) & 15(60.0) & 0(0) \\ 339(86.9) & 66(16.9) & 15(60.0) & 7(28.0) \\ 237(60.8) & 12(3.1) & 1(4.0) & 0(0) \\ 153(39.2) & 20(5.1) & 2(8.0) & 0(0) \\ 34(8.7) & 11(2.8) & 2(8.0) & 2(8.0)\end{array}$

Abbreviations: ECOG Eastern Cooperative Oncology Group, EGFR epidermal growth factor receptor, TKI tyrosine-kinase inhibitor

anti-EGFR monoclonal antibody, leading to an ORR of $30 \%$ and median PFS of 4.7 months revealed in a phase Ib/II trial [36, 37].

Though there were no statistical significant differences in PFS and OS between afatinib and erlotinib, afatinib was found to have better disease control and borderline better objective response as compared to erlotinib. Of much interest, more patients had worse performance status (ECOG 2) and were treated with 2 previous lines of chemotherapy in the afatinib group as compared to those who received erlotinib. They inherently had very 
limited treatment options because of their borderline physical fitness and capabilities. In fact 20 (80 \%) patients received afatinib as the last line of treatment before they succumbed to the disease and more patients received afatinib beyond disease progression as compared to those in the erlotinib group $(p=0.05)$. Nonetheless, they still enjoyed similar PFS and OS with afatinib as compared to those with better performance status who received erlotinib.

We found that age $\leq 70$ years and longer TTP to $1^{\text {st }}$ TKI therapy $\geq 18$ months were prognostic factors of longer PFS to $2^{\text {nd }}$ TKI therapy (irrespective of whether afatinib or erlotinib), in both univariate and multivariate analyses. Other factors especially the time interval between $1^{\text {st }}$ TKI and afatinib or erlotinib were not prognostic. This might be contrary to one postulation that longer interval between $1^{\text {st }}$ and $2^{\text {nd }}$ TKI may promote re-growth of TKI-sensitive clones leading to continued response when TKI was rechallenged. However this postulation has been gradually superseded by the notion of tumor rebiopsy to delineate the latest mutational status before initiation of further targeted treatment. We did not perform tumor rebiopsy before commencement of afatinib or erlotinib in our study as this was not mandatory according to LUX-Lung1 study. This may be one of our study limitations. Tumor rebiopsy shall become a norm before commencement of $2^{\text {nd }}$ EGFR-TKI therapy after failure to the first one especially when patients were advised to join the clinical trials using T790M-specific TKI [38]. The relatively small sample size was another limitation. In addition, comparison of afatinib with erlotinib was not performed in a randomized-controlled trial basis though data for the patients in the erlotinib cohort were prospectively collected. It is difficult to be carry out such randomized-controlled trial, however, having realized the very limited efficacy of erlotinib after prior failure to gefitinib shown in previous studies [26-30]. Notwithstanding, our study provided important clinical information on the efficacy and safety of afatinib as $2^{\text {nd }}$ TKI therapy and its comparable anti-tumor activity but with a different toxicity profile compared to erlotinib in this setting.

\section{Conclusion}

Our study demonstrated the ability of afatinib to prolong disease progression with similar survival outcomes but different toxicities compared to those who received erlotinib, and a comparable efficacy at least as comparable as that shown in LUX-Lung1 study.

\section{Abbreviations}

EGFR: epidermal growth factor receptor; TKI: tyrosine-kinase inhibitor: CUP, Compassionate use program; NSCLC: non-small-cell lung cancer; ECOG: Eastern Cooperative Oncology Group; ORR: objective response rate; DCR: disease control rate; PFS: progression-free survival; OS: overall survival;
TTP: time to progression; NPU: named patient use; PCR: polymerase chain reaction; RECIST: Response Evaluation Criteria for Solid Tumors; CT: computed tomography; CTCAE: Common Terminology Criteria for Adverse Events; SPSS: Statistical Package for Social Sciences.

\section{Competing interests}

The authors declare that they have no competing interests.

\section{Authors' contributions}

All authors fulfilled the authorship criteria with substantial contribution to the conception and study design. VHFL, DKCL, KOL, PML, TWL and DLWK recruited patients and collected the data. VHFL, TSC, DKLC and KOL performed statistical analysis of the data. All the authors drafted the manuscript, and all read and approved the final manuscript before submission.

\section{Acknowledgments}

We thanked Boehringer-Ingelheim Pharma GmbH, Ingelheim \& Co. KG, Germany to supply afatinib to our patients in this study.

Received: 7 October 2015 Accepted: 17 February 2016

Published online: 24 February 2016

\section{References}

1. Mok TS, Wu YL, Thongprasert S, Yang CH, Chu DT, Saijo N, et al. Gefitinib or carboplatin-paclitaxel in pulmonary adenocarcinoma. N Eng J Med. 2009; 361:947-57.

2. Maemondo M, Inoue A, Kobayashi K, Sugawara S, Oizumi S, Isobe H, et al. Gefitinib or chemotherapy for non-small cell lung cancer with mutated EGFR. N Engl J Med. 2010;362:2380-8.

3. Mitsudomi T, Morita S, Yatabe Y, Negoro S, Okamoto I, Tsurutani J, et al. Gefitinib versus cisplatin plus docetaxel in patients with non-small lung cancer harboring mutations of the epidermal growth factor receptor (WJTOG3405): An open label, randomized phase 3 trial. Lancet Oncol. 2010;11:121-8.

4. Zhou C, Wu YL, Chen G, Feng J, Liu XO, Wang C, et al. Erlotinib versus chemotherapy as first-line treatment for patients with advanced EGFR mutation-positive non-small cell lung cancer (OPTIMAL, CTONG-0802): A multicenter, open-label, randomized, phase 3 study. Lancet Oncol. 2011; 12:735-42.

5. Rosell R, Carcereny E, Gervais R, Vergnenegre A, Massuti B, Felip E, et al. Erlotinib versus standard chemotherapy as first-line treatment for European patients with advanced EGFR mutation-positive non-small-cell lung cancer (EURTAC): a multicenter, open-label, randomized phase 3 trial. Lancet Oncol. 2012:13:239-46.

6. Fukuoka M, Wu YL, Thongprasert S, Sunpaweravong P, Leong SS, Sriuranpong $V$, et al. Biomarker analyses and final overall survival results from a phase III, randomized, open-label, first-line study of gefitinib versus carboplatin/paclitaxel in clinically selected patients with advanced non-small cell lung cancer in Asia (IPASS). J Clin Oncol. 2011;29:2866-74.

7. Han JY, Park K, Kim SW, Lee DH, Kim HY, Kim HT, et al. First-SIGNAL: First-line single-agent iressa versus gemcitabine and cisplatin trial in never-smokers with adenocarcinoma of the lung. J Clin Oncol. 2012;30:1122-28.

8. Pao W, Miller VA, Politi KA, Riely GJ, Somwar R, Zakowski MF, et al. Acquired resistance of lung adenocarcinomas to gefitinib or erlotinib is associated with a second mutation in the EGFR kinase domain. PLoS Med. 2005:2:e73.

9. Kobayashi S, Boggon TJ, Dayaram T, Jänne PA, Kocher O, Meyerson M, et al. EGFR mutation and resistance of non-small-cell lung cancer to gefitinib. N Engl J Med. 2005;352:786-92.

10. Oxnard GR, Arcila ME, Sima CS, Riely GJ, Chmielecki J, Kris MG, et al. Acquired resistance to EGFR tyrosine kinase inhibitors in EGFR-mutant lung cancer: distinct natural history of patients with tumors harboring the T790M mutation. Clin Cancer Res. 2011;17:1616-22.

11. Li D, Ambrogio L, Shimamura T, Kubo S, Takahashi M, Chirieac LR, et al. BIBW2992, an irreversible EGFR/HER2 inhibitor highly effective in preclinical lung cancer models. Oncogene. 2008;27:4702-11.

12. Yap TA, Vidal L, Adam J, Stephens P, Spicer J, Shaw H, et al. Phase I trial of the irreversible EGFR and HER2 kinase inhibitor BIBW 2992 in patients with advanced solid tumors. J Clin Oncol. 2010;28:3965-72.

13. Miller VA, Hirsh V, Cadranel J, Chen YM, Park K, Kim SW, et al. Afatinib versus placebo in patients with advanced, metastatic non-small-cell lung cancer after failure of erlotinib, gefitinib, or both, and one or two lines of 
chemotherapy (LUX-Lung 1): a phase 2b/3 randomised trial. Lancet Oncol. 2012;13:528-38

14. Khan F, Ottensmeier C, Popat S, Dua D, Dorey N, Ellis S, et al. Afatinib use in non-small cell lung cancer previously sensitive to epidermal growth factor receptor inhibitors: The United Kingdom Named Patient Programme. Eur J Cancer. 2014:50:1717-21.

15. Tam IY, Chung LP, Suen WS, Wang E, Wong MC, Ho KK, et al. Distinct epidermal growth factor receptor and KRAS mutation patterns in non-small cell lung cancer patients with different tobacco exposure and clinicopathologic features. Clin Cancer Res. 2006;12:1647-53.

16. Eisenhauer EA, Therasse P, Bogaerts J, Schwartz LH, Sargent D, Ford R, et al. New response evaluation criteria in solid tumours; revised RECIST guideline (version 1.1). Eur J Cancer. 2009;45:228-47.

17. Common Terminology Criteria for Adverse Events (CTCAE) Version 4.0. http://ctep.cancer.gov/protocolDevelopment/electronic_applications/ctc. htm (assessed May 28, 2009)

18. Chmielecki J, Foo J, Oxnard GR, Hutchinson K, Ohashi K, Somwar R, et al. Optimization of dosing for EGFR-mutant non-small cell lung cancer with evolutionary cancer modeling. Sci Transl Med. 2011;3:90ra59.

19. Zakowski MF, Ladanyi M, Kris MG. EGFR mutations in small-cell lung cancers in patients who have never smoked. N Engl J Med. 2006;355:213-5.

20. Sequist $L V$, Waltman BA, Dias-Santagata D, Digumarthy $S$, Turke AB, Fidias $P$, et al. Genotypic and histological evolution of lung cancers acquiring resistance to EGFR inhibitors. Sci Transl Med. 2011;3:75ra26.

21. Bean J, Brennan C, Shih JY, Riely G, Viale A, Wang L, et al. MET amplification occurs with or without T790M mutations in EGFR mutant lung tumors with acquired resistance to gefitinib or erlotinib. Proc Natl Acad Sci. 2007;104: 20932-7.

22. Engelman JA, Zejnullahu K, Mitsudomi T, Song Y, Hyland C, Park JO, et al. MET amplification leads to gefitinib resistance in lung cancer by activating ERBB3 signaling. Science. 2007;316:1039-43.

23. Takezawa K, Pirazzoli V, Arcila ME, Nebhan CA, Song X, de Stanchina E, et al. HER2 amplification: a potential mechanism of acquired resistance to EGFR inhibition in EGFR mutant lung cancers that lack the second-site EGFR T790M mutation. Cancer Discov. 2012;2:922-33.

24. Ohashi K, Sequist LV, Arcila ME, Moran T, Chmielecki J, Lin YL, et al. Lung cancers with acquired resistance to EGFR inhibitors occasionally harbor BRAF mutations but lack mutations in KRAS, NRAS, or MEK1. Proc Natl Acad Sci. 2012;109:E2127-33.

25. Hata AKN, Katakami N, Yoshioka H, Takeshita J, Tanaka K, Nanjo S, et al. Rebiopsy of non-small cell lung cancer patients with acquired resistance to EGFR-TKI: Comparison between T790M mutation-positive and -negative populations. J Clin Oncol. 2012;30(15_Suppl);abstr 7528 .

26. Riely GJ, Kris MG, Zhao B, Akhurst T, Milton DT, Moore E, et al. Prospective assessment of discontinuation and reinitiation of erlotinib or gefitinib in patients with acquired resistance to erlotinib or gefitinib followed by the addition of everolimus. Clin Cancer Res. 2007;13:5150-5.

27. Yokouchi H, Yamazaki K, Kinoshita I, Konishi J, Asahina H, Sukoh N, et al. Clinical benefit of readministration of gefitinib for initial gefitinib-responders with non-small cell lung cancer. BMC Cancer. 2007;7:51.

28. Cho BC, Im CK, Park MS, Kim SK, Chang J, Park JP, et al. Phase II study of erlotinib in advanced non-small-cell lung cancer after failure of gefitinib. J Clin Oncol. 2007;25:2528-33.

29. Lee DH, Kim SW, Suh C, Yoon DH, Yi EJ, Lee JS. Phase II study of erlotinib as a salvage treatment for non-small-cell lung cancer patients after failure of gefitinib treatment. Ann Oncol. 2008;19:2039-42.

30. Costa DB, Nguyen KS, Cho BC, Sequist LV, Jackman DM, Riely GJ, et al. Effects of erlotinib in EGFR mutated non-small cell lung cancers with resistance to gefitinib. Clin Cancer Res. 2008;14:7060-7.

31. Pfizer announces 2 top-line results from 2 phase III trials of dacomitinib in patients with refractory advanced non-small cell lung cancer [press release]. New York, NY: Pfizer Inc; January 27, 2014.

32. Soria J, Sequist LV, Gadgeel S, Goldman J, Wakelee H, Varga A, et al. First-inhuman evaluation of CO-1686, an irreversible highly selective TKI of mutations of EGFR (activating and T790M). 15th World Conference on Lung Cancer; October 27-30 2013; Sydney, New South Wales, Australia.

33. Ranson M, Pao W, Kim D, Kim DW, Kim SW, Ohe Y, et al. AZD9291: an irreversible, potent and selective tyrosine kinase inhibitor of activating EGFR and resistance T790M mutations in advanced NSCLC. 15th World Conference on Lung Cancer; October 27-30 2013; Sydney, New South Wales, Australia.
34. Sequist LV, Soria JC, Goldman JW, Wakelee HA, Gadgeel SM, Varga A, et al. Rociletinib in EGFR-mutated non-small-cell lung cancer. N Engl J Med. 2015; 372:1700-9.

35. Jänne PA, Yang JC, Kim DW, Planchard D, Ohe Y, Ramalingam SS, et al. AZD9291 in EGFR inhibitor-resistant non-small-cell lung cancer. N Engl J Med. 2015;372:1689-99.

36. Janjigian YY, Groen HJ, Horn L, Smit EF, Fu Y, Wang F, et al. Activity and tolerability of afatinib (BIBW 2992) and cetuximab in NSCLC patients with acquired resistance to erlotinib or gefitinib. J Clin Oncol. 2011;29 (suppl; abstr 7525).

37. Janjigian YY, Smit EF, Horn L, Groen HJ, Camidge R, Gettinger S, et al. Activity of afatinib/cetuximab in patients (pts) with EGFR mutant non-small cell lung cancer (NSCLC) and acquired resistance (AR) to EGFR inhibitors. Ann Oncol. 2012;23 (suppl 9;abstr 12270).

38. Yu HA, Arcila M, Rekhtman N, Sima CS, Zakowski MF, Pao W, et al. Analysis of Tumor Specimens at the Time of Acquired Resistance to EGFR TKI therapy in 155 patients with EGFR mutant lung cancers. Clin Cancer Res. 2013;19:2240-47.

\section{Submit your next manuscript to BioMed Central and we will help you at every step:}

- We accept pre-submission inquiries

- Our selector tool helps you to find the most relevant journal

- We provide round the clock customer support

- Convenient online submission

- Thorough peer review

- Inclusion in PubMed and all major indexing services

- Maximum visibility for your research

Submit your manuscript at www.biomedcentral.com/submit
( ) BioMed Central 